\title{
Sentra Mebel Sebagai Destinasi Wisata Dengan Pendekatan ArSiteKtur RegionalisMe Di JUWIRING, KLATEN
}

\author{
Fitria Khairanisa, Hadi Setyawan, Ahmad Farkhan \\ Program Studi Arsitektur \\ Universitas Sebelas Maret Surakarta \\ Email : fitriakhairanisa@gmail.com
}

\begin{abstract}
The design background of Furniture Center at Juwiring is due to many of furniture craftmen that spread over in Juwiring. There is no center place to make furniture exhibition at Juwiring, it makes craftsmen have difficulty in marketing, and so do the consumer that have difficulty in search for information of furniture from Juwiring. The issue of design are: how to appear the image of a building that has a characteristic of Juwiring to be an attractive tourism destination at Juwiring. The method used is Defamiliarisasi method from Architectural Regionalism theory. The analysis design begins with gathering the potential of characteristic Juwiring, then decomposing to architectural building components. The result are design concept of furniture centers with facilities and infrastructure as a tourism destination. The concept of the building shows the characteristic of Juwiring which comes from the decomposition potential forms around Juwiring like joglo, pendhapa, Juwiring's umbrella, and Prambanan.
\end{abstract}

Keywords: Appearance Building, Juwiring's Characteristic, Furniture Craftsmen at Juwiring, Regionalism Architecture, Tourism Destination.

\section{PENDAHULUAN}

Sektor industri merupakan salah satu mata pencaharian utama warga yang berada di Juwiring, selain bidang pertanian. Data Monografi Kecamatan Juwiring, terdapat 978 unit usaha mebel di Juwiring yang tersebar di 8 dukuh hingga tahun 2008 (BAPPEDA Klaten, 2010). Dari industri berskala kecil di rumah-rumah warga hingga industri skala besar. Mebel kerajinan warga Juwiring memiliki mutu dan kualitas tinggi yang bernilai jual tinggi. Bahkan beberapa produknya mampu menembus pasar Internasional.

Industri mebel di Juwiring memiliki potensi yang tinggi untuk meningkatkan perekonomian masyarakat. Selain itu, daerah Juwiring berpotensi sebagai jalur perdagangan antara kabupaten Klaten dan Sukoharjo karena letaknya yang strategis sehingga menjadi penghubung antara daerah Kota Klaten dan Sukoharjo.

Sentra Mebel ini bertujuan sebagai tempat promosi bagi industri-industri yang tersebar di Juwiring untuk dapat dipusatkan dalam satu tempat, sehingga memudahkan konsumen untuk memperoleh informasi yang dibutuhkan. Selain itu, dapat membantu pemerintah dalam mengawasi industri mebel di Juwiring.

Sentra Mebel ini juga dapat dikembangkan menjadi salah satu destinasi wisata yang menarik. Pendekatan Arsitektur Regionalisme digunakan untuk memperkuat nilai-nilai budaya dan ciri khas daerah Klaten sebagai daya tarik bagi wisatawan. Wisatawan dapat menikmati suasana khas Juwiring sambil berbelanja atau melihat-lihat produk mebel

Proses transformasi bentuk bangunan tidak terlepas dari keberadaan lingkungan sekitar Juwiring dan Klaten. Dengan pendekatan Arsitektur Regionalisme, potensi sekitar tersebut diangkat untuk desain bentuk bangunan dan menjadi karakteristik bagi bangunan yang akan direncanakan.

Karakteristik dari potensi lingkungan sekitar yang menjadi inspirasi bangunan yaitu joglo, pendhapa, payung hias khas Juwiring, dan Candi Prambanan. Kemudian karakter daerah tersebut diuraikan dengan memahami komponen pembentuk arsitekturalnya, baik tatanan fisik yang nampak dalam ragam arsitekturnya maupun tatanan kosmologis yang mendasari terbentuknya ruang. Kemudian diterapkan pada bangunan Sentra Mebel yang direncanakan melalui beberapa elemen seperti 
bentuk, proporsi, bukaan, warna, tekstur dan material.

\section{METODE}

Regionalisme merupakan peleburan antara yang lama dan yang baru. Menurut Curtis (1996), Arsitektur Regionalisme diharapkan dapat menghasilkan bangunan yang bersifat abadi, melebur, atau menyatu antara yang lama dan yang baru, antara regional dan universal.

Metode defamiliarisasi pada pendekatan Arsitektur Regionalisme bekerja dengan cara memilih elemen regional yang memiliki potensi menunjukkan ciri khas sebuah daerah, dan menggunakannya secara baru.

Menurut Frampton (dalam Tzonis, 2003), langkah-langkah metode defamiliarisasi yang dilakukan untuk analisis konsep bangunan Sentra Mebel dengan pendekatan Arsitektur Regionalisme yaitu pengenalan, penguraian, dan pembentukan kembali.

A. Tahap Pengenalan (identifying)

Identifikasi arsitektur yaitu memahami komponen pembentuk arsitektur baik tatanan fisik yang nampak dalam ragam arsitekturnya maupun tatanan kosmologis yang mendasari terbentuknya ruang. Menurut Ching (2000), ada beberapa elemen arsitektural yang dapat membentuk karakter. Penerapan karakter pada arsitektural dapat dibentuk melalui beberapa elemen seperti bentuk, proporsi, bukaan, warna, tekstur dan material.

B. Tahap Penguraian (decomposing)

Dekomposisi atau penguraian merupakan bagian dari rangkaian proses yang dimaksudkan untuk mendapatkan esensi dari bentuk yang hadir sehingga didapat hakikat dari keunikan tanpa harus terbelenggu pada tipologi bentuk.

C. Tahap Pembentukan Kembali (recomposing)

Tahap pembentukan kembali akan berangkat dari tatanan nilai yang membentuk ruang, atau tatanan tektonika material yang membentuk citra. Penyusunan ini tidak terpaku pada batasan bentuk luar karena esensi terpenting dari pembentuk rancangan lama tersebut telah didapatkan melalui serangkaian pembacaan objek.

\section{ANALISIS}

\subsection{Analisis Peruangan}

Analisis peruangan disesuaikan dengan hasil pengumpulan data dan wawancara dilapangan serta penambahan persyaratan lain yang diperlukan sesuai dengan kebutuhan untuk mewadahi kegiatan wisata.

\subsection{Analisis Pengguna}

\subsubsection{Pengelola}

Pengelola merupakan individu yang tergabung dalam suatu badan yang mempunyai tugas mengelola, mengatur, mengorganisir pusat kerajinan agar dapat berjalan baik.

\subsubsection{Pengrajin}

Pengrajin mebel di Kecamatan Juwiring yang membutuhkan media pemasaran yaitu Sentra Mebel ini. Sistem kepemilikan kios di Sentra Mebel menggunakan sistem sewa untuk pengrajin pengusaha mebel.

\subsubsection{Pengunjung}

Pengunjung

dikelompokkan berdasarkan dari kelompok asal dan tujuan berkunjung, yaitu:

1. Masyarakat Umum

Masyarakat umum di sini yang dimaksud adalah orang-orang atau penduduk sekitar yang datang dan berkunjung ke Sentra Mebel dengan tujuan untuk berekreasi atau sekedar menikmati fasilitas yang ada.

2. Wisatawan

Wisatawan yang berkegiatan dalam Sentra Mebel ini terdiri dari wisatawan domestik dan mancanegara.

3. Pembeli

Pembeli yang berkunjung untuk keperluan mencari dan membeli produk mebel khas Juwiring.

\subsection{Analisis Daya Tampung}

Berdasarkan data jumlah kunjungan wisata di Klaten pada 4 tahun terakhir menunjukan penurunan hingga tahun 2013. Kemudian jumlah wisatawan di Klaten mengalami kenaikan drastis pada tahun 2014.

Berdasarkan jumlah kunjungan wisata per tahun, maka jumlah kunjungan wisata per hari diperoleh sebanyak 879 kunjungan wisata. Dengan demikian, jumlah pengunjung pada Sentra Mebel yang direncanakan dapat diasumsikan sebanyak 87 pengunjung setiap hari. 


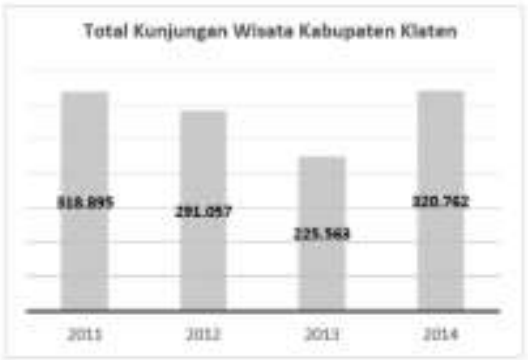

Bagan 1. Jumlah Kunjungan Wisata Klaten Tahun 2011-2014.

\subsection{Analisis Besaran Ruang}

Berdasarkan standar besaran ruang bersumber dari Neufert Architect's Data (NAD), Time Saver Standard (TSS) dan preseden, maka didapatkan kebutuhan besaran ruang sebagai berikut.

Tabel 1. Besaran Ruang

\begin{tabular}{|c|c|c|}
\hline & Jenis Ruang & $\begin{array}{c}\text { Besaran } \\
\text { Ruang } \\
\left(\mathrm{M}^{2}\right)\end{array}$ \\
\hline$\checkmark$ & $\begin{array}{l}\text { Kelompok Ruang } \\
\text { Zona Penerima }\end{array}$ & 2664,4 \\
\hline$\checkmark$ & $\begin{array}{l}\text { Kelompok Ruang } \\
\text { Zona Display }\end{array}$ & 2855 \\
\hline$\checkmark$ & $\begin{array}{l}\text { Kelompok Ruang } \\
\text { Zona Akomodasi } \\
\text { Wisata }\end{array}$ & 735,3 \\
\hline$\checkmark$ & $\begin{array}{l}\text { Kelompok Ruang } \\
\text { Zona Pengelola }\end{array}$ & 220,2 \\
\hline$\checkmark$ & $\begin{array}{l}\text { Kelompok Ruang } \\
\text { Zona Pelayanan }\end{array}$ & 454,7 \\
\hline$\checkmark$ & $\begin{array}{l}\text { Kelompok Ruang } \\
\text { Zona Me }\end{array}$ & 218,75 \\
\hline & Jumlah & 7148,35 \\
\hline
\end{tabular}

Pada Tabel 1. Besaran ruang, didapatkan total kebutuhan ruang untuk Sentra Mebel adalah sebesar 7148,35 m2.

Area lokasi yang direncanakan adalah sebesar $11.150 \mathrm{~m} 2$, sehingga mencukupi kebutuhan ruang yang direncanakan.

\subsection{Analisis Lokasi}

Lokasi tapak berada di Jalan SerenanSukoharjo, Desa Gondangsari, Kecamatan Juwiring, Kabupaten Klaten. Untuk mendapatkan lokasi yang tepat, diperlukan beberapa pertimbangan yang sesuai dengan fungsi dan tujuan dari perencanaan kawasan.
1. Tujuan: lokasi tapak yang sesuai untuk fungsi dan tujuan perencanaan Sentra Mebel di Juwiring.

2. Dasar pertimbangan:

a. Sesuai dengan rencana kota.

b.Nilai ekonomis.

c. Tingkat aksesibilitas atau pencapaian yang mudah.

d.Dekat dengan pusat industri mebel di Juwiring.

e. Kelengkapan utilitas.

f. View yang menarik.

3. Hasil analisis:

Berdasarkan kriteria tersebut, maka didapatkan tapak terpilih berikut:

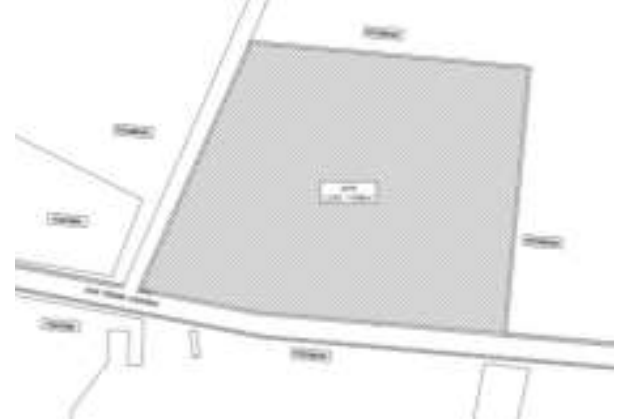

Gambar 1. Tapak Terpilih.

Pada Gambar 1. Tapak terpilih berada di jalan Serenan-Sukoharjo yang merupakan jalan utama penghubung Sukoharjo dan Klaten.

\subsection{Analisis Pencapaian}

Main entrance berfungsi sebagai jalur keluar-masuk pengunjung pada tapak. Service entrance digunakan sebagai jalur keluarmasuk pengelola dan loading dock barang mebel.

1. Tujuan: main entrane dan service entrance yang nyaman dan aman bagi pengguna.

2. Dasar Pertimbangan: Kemudahan pencapaian, sirkulasi yang nyaman dan aman, pengelompokkan kegiatan.

3. Hasil analisis

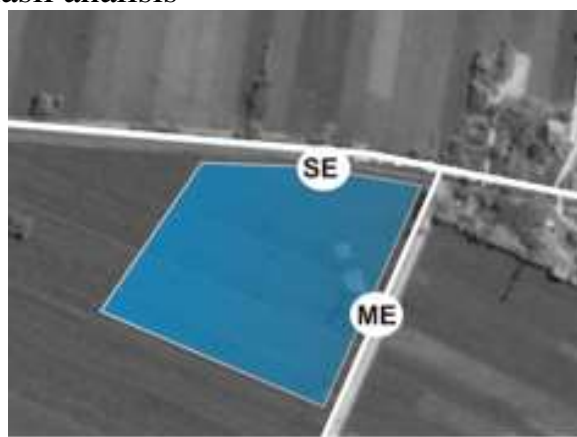

Gambar 2. Pola Pencapaian. 
Pada Gambar 2, Main Entrance berada di sebelah utara agar mudah ditemukan dan diakses oleh pengunjung. Sedangkan Site Entrance berada di sebelah timur agar tidak menganggu sirkulasi pengunjung.

\subsection{Analisis Pemintakatan (Penzoningan)}

Pemintakatan digunakan sebagai acuan dalam penataan peruangan dengan memperhatikan beberapa pertimbangan penting dalam peletakannya.

1. Tujuan: mintakat (zoning) yang berdasarkan kebutuhan fungsi ruang pada tapak.

2. Dasar pertimbangan: analisis peruangan, analisis pencapaian, analisis view.

3. Hasil analisis

Konsep pemintakatan menggunakan keseimbangan simetris seperti pada rumah tradisional Jawa, dengan hirarki ruang publik menuju privat.

Pada Gambar 3, zona penerima sesuai dengan tuntutan dari pengunjung untuk kemudahan aksesibilitas dari jalan utama. Zona showroom berada pada tengah tapak dengan mempertimbangkan kemudahan akses dari zona lain. Zona akomodasi wisata berada pada zona yang menguntungkan view dari tapak dan view dari luar tapak. Zona pelayanan berada di dekat Service Entrance (SE) untuk kemudahan aksesibilitas menuju zona pelayanan tanpa mengganggu kegiatan pengunjung. Zona ME berada di bagian belakang tapak dengan pertimbangan fungsi kegiatan dalam bangunan agar tidak mengganggu kegiatan lain.

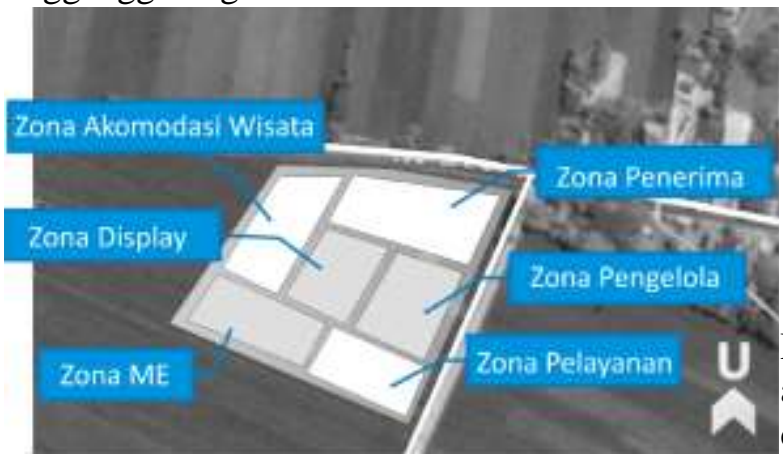

Gambar 3. Pola Pemintakatan.

\subsection{Analisis Denah Bangunan}

Proses transformasi denah menyesuaikan dengan citra tampilan yang ingin ditunjukkan didasari oleh konsep karakter khas Juwiring, yaitu dari pemaknaan Candi Prambanan. peletakannya.

1. Tujuan: denah bangunan yang sesuai dengan fungsi dan mampu menunjukkan karakter khas Juwiring.

2. Dasar pertimbangan: inspirasi dari potensi daerah sekitar, analisis pola pencapaian, analisis kebutuhan ruang.

3. Hasil analisis

Denah bangunan merupakan transformasi dari denah candi yang pernah ada di Prambanan.

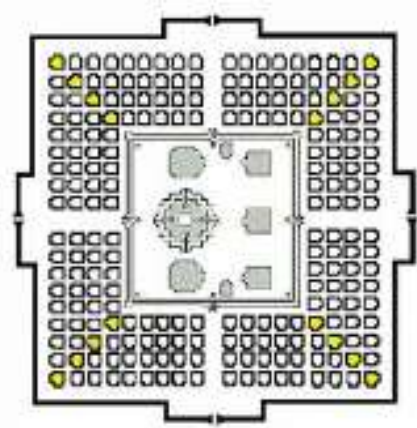

Gambar 4. Denah Candi Prambanan.

Pada Gambar 4, denah Candi Prambanan memiliki bentuk persegi dengan 1000 candi yang pernah berada di Prambanan, letaknya mengelilingi 3 candi utama yang berada di tengah dengan keseimbangan simetris terpusat. Untuk menuju candi utama dapat melalui 4 jalur yang berada di 4 sisi yaitu utara, timur, selatan, dan barat.

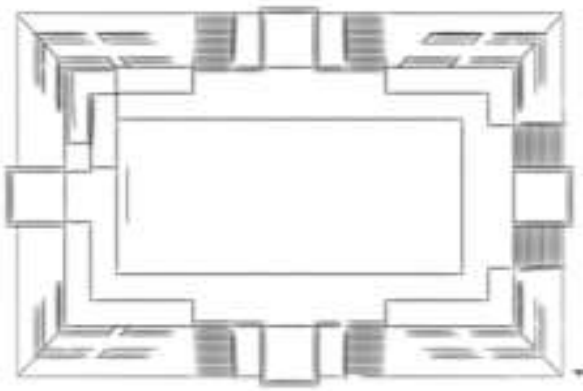

Gambar 5. Denah Bangunan Sentra Mebel.

Pada Gambar 5, denah bangunan Sentra Mebel berbentuk persegi panjang, bertujuan agar ruang pameran dapat terlihat lebih luas dan memanjang sehingga dapat menunjukkan alur sirkulasi pada pengunjung pameran. Terdapat 4 sisi bukaan yang dapat menjadi pintu masuk pada 4 sisi yaitu utara, timur, selatan, dan barat. 


\subsection{Analisa Bentuk Massa}

Proses transformasi bentuk bangunan menyesuaikan dengan citra tampilan yang ingin ditunjukkan didasari oleh konsep karakter khas Juwiring, yaitu dari pemaknaan bentuk Candi Prambanan.

1. Tujuan: bentuk massa bangunan.

2. Dasar pertimbangan: bentuk dasar showroom, inspirasi dari potensi sekitar tapak.

3. Hasil analisis

Pada Gambar 6, gambar potongan Candi Prambanan menunjukan tangga yang berundak-undak. Tangga bangunan Sentra Mebel mengadopsi bentuk candi yang berundak-undak, untuk membuat bangunan terlihat monumental.

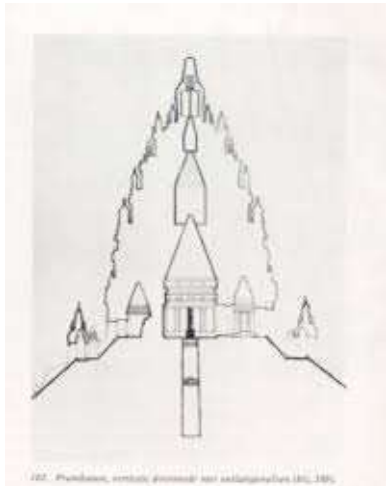

Gambar 6. Bentuk Candi Pambanan.

Pada Gambar 7, terdapat tangga dari sisi luar bangunan yang dapat digunakan pengunjung untuk langsung menuju ruang pameran di lantai 2.
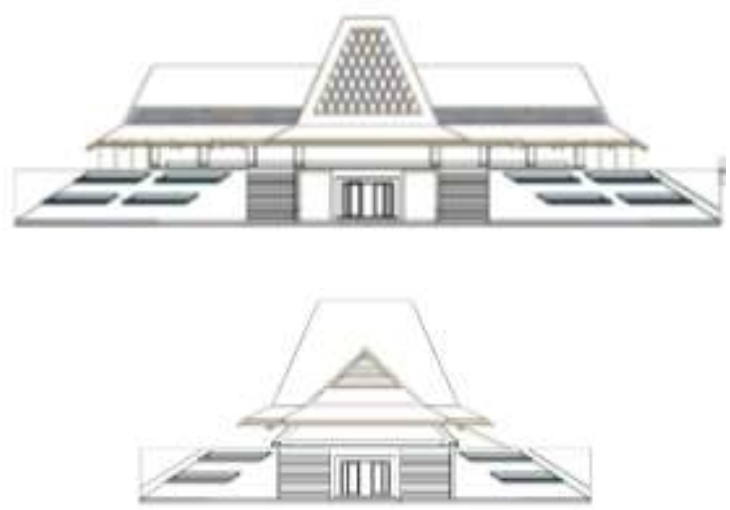

Gambar 7. Bentuk Massa Bangunan Sentra Mebel.

\subsection{Analisis Bentuk Atap}

Proses transformasi bentuk atap menyesuaikan dengan citra tampilan yang ingin ditunjukkan didasari oleh konsep karakter khas Juwiring, yaitu dari pemaknaan atap joglo dan pendhapa.

1. Tujuan: fasad yang estetis dan memiliki ciri khas Juwiring.

2. Dasar pertimbangan: inspirasi dari potensi sekitar tapak, luas ruangan yang tertutup atap, struktur atap.

3. Hasil analisis

Pada Gambar 8, bentuk atap joglo menciptakan ruang yang luas sehingga ditransformasikan seperti pendhapa untuk menjadi ruang pameran mebel lantai 2 .

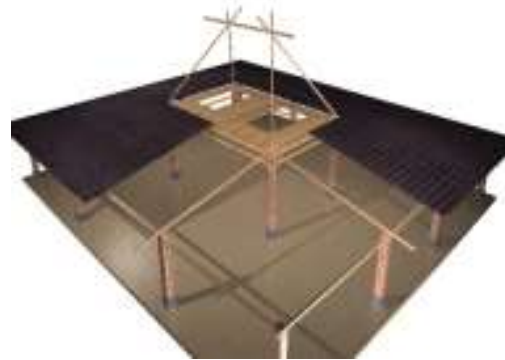

Gambar 8. Bentuk Pendhapa dan Atap Joglo.

Pada Gambar 9, saka guru menjadi penopang struktur dari lantai 1.

Pada Gambar 10, lantai 2 yang merupakan atap difungsikan sebagai pendhapa, memiliki tiang penampang atap yang mengikuti kemiringan atap.

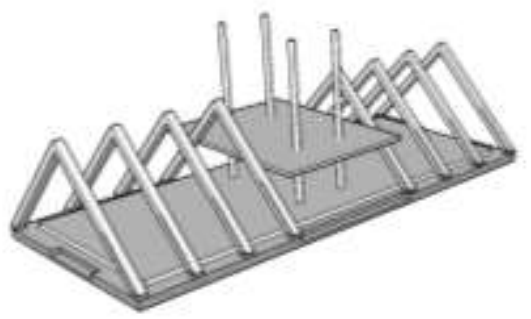

Gambar 9. Struktur Atap dan Lantai 2 Bangunan Sentra Mebel.

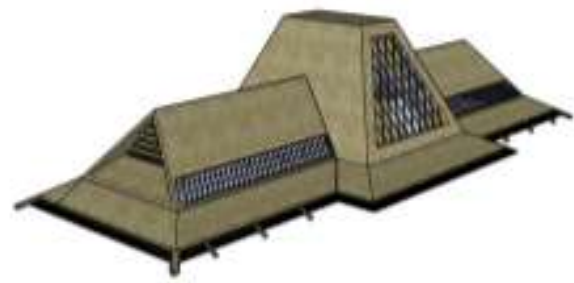

Gambar 10. Penutup Atap. 


\subsection{Analisa Bukaan}

Bangunan memiliki karakter yang menggunakan konsep makna payung hias khas Juwiring, diwujudkan dengan memberikan kualitas bukaan yang dapat memberikan kesan lapang, bebas, dan bermasyarakat.

1. Tujuan: kualitas bukaan pada massa bangunan.

2. Dasar pertimbangan: penghawaan alami optimal, pencahayaan alami optimal.

3. Hasil analisis

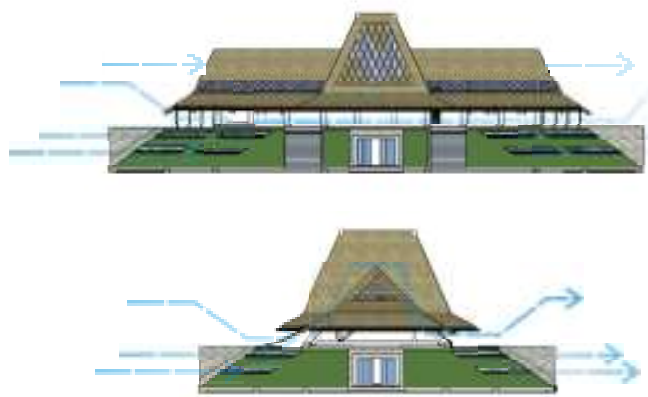

Gambar 11. Pola Penghawaan Alami.

Pada Gambar 11, terlihat letak bukaan berada pada 4 sisi bangunan agar terjadi penghawaan silang dalam ruangan, serta untuk memaksimalkan penghawaan alami dan pencahayaan alami pada lantai 1 dan lantai 2 .

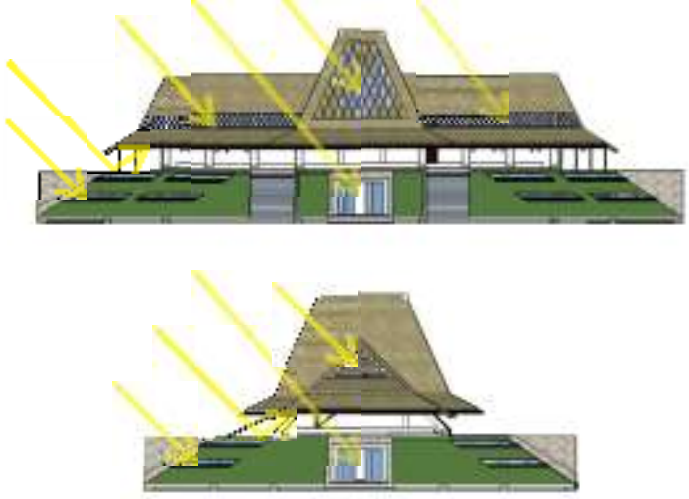

Gambar 12. Pola Pencahayaan Alami.

Pada Gambar 12, terlihat lantai 1 memiliki bukaan berupa pintu masuk yang berada di 4 sisi bangunan, serta terdapat jendela dan kisi-kisi untuk pencahayaan alami dan penghawaan alami. Pada lantai 2 dindingnya merupakan atap, sehingga ruangan setengah terbuka.

\subsection{Analisa Sirkulasi dalam Bangunan}

1. Tujuan: pola sirkulasi dalam bangunan, khususnya adalah pola sirkulasi yang mendukung kegiatan pemasaran produk mebel khas Juwiring yaitu pada area showroom dan ritel.

2. Dasar Pertimbangan:

a. Pola sirkulasi yang aman dan memudahkan pengguna dalam berkeliling area ritel dan showroom.

b. Pola sirkulasi berdasarkan pada alur kegiatan.

c. Pola sirkulasi yang memudahkan pengguna dalam berinteraksi secara sosial maupun antar individu.

d. Pola kelancaran sirkulasi.

3. Hasil analisis

Pada Gambar 13, tujuan sirkulasi bangunan untuk menguntungkan pemasaran, maka jalur sirkulasi yang tepat untuk Sentra Mebel di Juwiring seperti gambar ilustrasi di bawah. Dengan jalur sirkulasi seperti ini, semua ritel dan showroom dapat dilewati pengunjung agar dapat menguntungkan pemasaran.

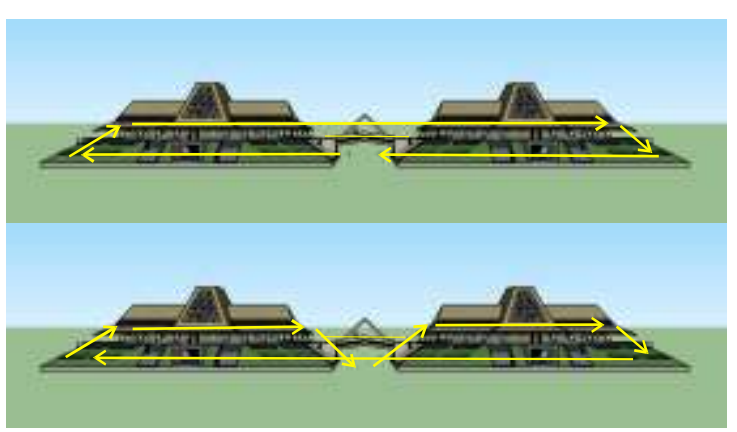

Gambar 13. Pola Sirkulasi dalam Bangunan.

\section{KESIMPULAN (KONSEP DESAIN)}

Dalam upaya membantu tumbuh kembangnya perekonomian di daerah Juwiring. Sentra Mebel bertujuan sebagai tempat promosi bagi industri-industri yang tersebar di Juwiring untuk dapat dipusatkan dalam satu tempat, sehingga memudahkan masyarakat untuk memperoleh informasi yang dibutuhkan. Selain itu, dapat membantu pemerintah dalam mengawasi industri mebel di Juwiring.

Pada Gambar 14, kegiatan industri mebel di Juwiring yang dipusatkan pada Sentra Mebel, dapat dikembangkan menjadi 
salah satu destinasi wisata yang menarik. Dengan pendekatan Arsitektur Regionalisme untuk memperkuat nilai-nilai budaya dan ciri khas daerah Klaten, sebagai daya tarik bagi wisatawan. Wisatawan dapat menikmati suasana sambil berbelanja produk mebel yang memiliki ciri khas dari Klaten.

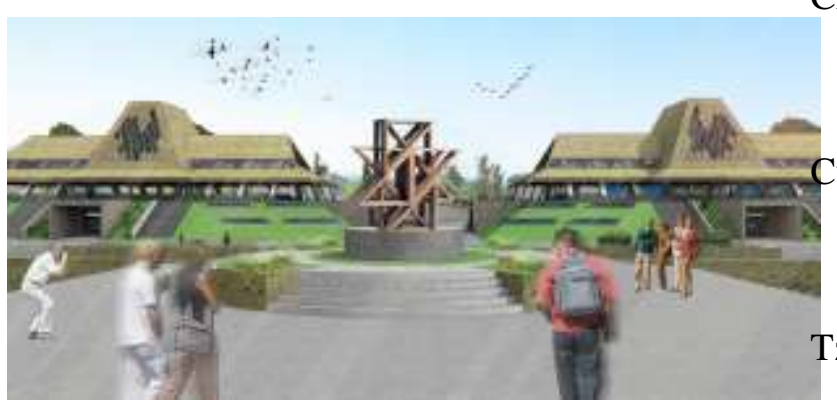

Gambar 14. Gambar Perspektif dari Pintu Masuk.

Pada Gambar 15, konsep rancangan Sentra Mebel menyesuaikan dengan citra tampilan yang ingin ditunjukkan didasari oleh konsep karakter khas Juwiring, yaitu dari pemaknaan atap joglo, pendhapa, Candi Prambanan, dan payung hias khas Juwiring.

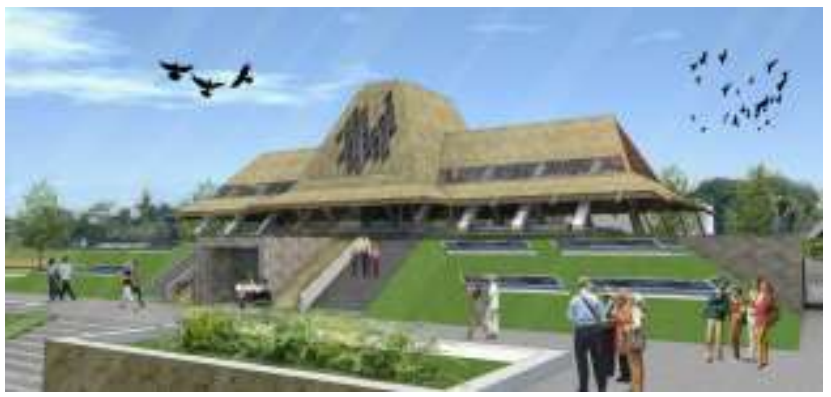

Gambar 15. Gambar Perspektif Bangunan.

Dari hasil analisa serta hasil korelasi dari beberapa data di atas, maka diperoleh hasil berupa rancangan Sentra Mebel di Juwiring sebagai berikut.

Nama bangunan: Sentra Mebel
Lokasi
: Jl. Serenan-Sukoharjo
Luas Lahan
: $11.150 \mathrm{~m}^{2}$
Daya Tampung : 100 pengunjung
Kegiatan : Pameran mebel, wisata, jual- beli.

\section{REFERENSI}

Badan Perencana Daerah Kabupaten Klaten. 2010. Laporan Kemajuan Rencana Induk Pengembangan Pariwisata (RIPP) Kabupaten Klaten. Klaten: Pemerintah Kabupaten Klaten.

Ching, D.K., Francis. 2000. Arsitektur Bentuk, Ruang, dan Tatanan; edisi kedua. Jakarta: Penerbit Erlangga.

Curtis, Wiliam. 1996. Regionalism in Architecture, editor Robert Powel. Singapore: Concept Media.

Tzonis, Alexander and Liane Lefaivre. 2003. Critical Regionalism: Architecture and Identity in a Globalised World 